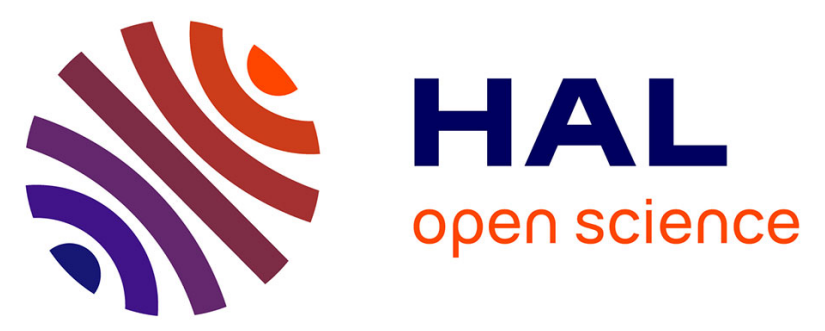

\title{
Cold Atmospheric Plasma Parameters Investigation for Efficient Drug Delivery in HeLa Cells
}

Vinodini Vijayarangan, Anthony Delalande, Sébastien Dozias, Jean-Michel Pouvesle, Chantal Pichon, Eric Robert

\section{- To cite this version:}

Vinodini Vijayarangan, Anthony Delalande, Sébastien Dozias, Jean-Michel Pouvesle, Chantal Pichon, et al.. Cold Atmospheric Plasma Parameters Investigation for Efficient Drug Delivery in HeLa Cells. IEEE Transactions on Radiation and Plasma Medical Sciences, 2018, 2 (2), pp.109-115. 10.1109/TRPMS.2017.2759322 . hal-01940672

\section{HAL Id: hal-01940672 \\ https://hal.science/hal-01940672}

Submitted on 3 Jun 2021

HAL is a multi-disciplinary open access archive for the deposit and dissemination of scientific research documents, whether they are published or not. The documents may come from teaching and research institutions in France or abroad, or from public or private research centers.
L'archive ouverte pluridisciplinaire HAL, est destinée au dépôt et à la diffusion de documents scientifiques de niveau recherche, publiés ou non, émanant des établissements d'enseignement et de recherche français ou étrangers, des laboratoires publics ou privés. 


\title{
Cold Atmospheric Plasma Parameters Investigation for Efficient Drug Delivery in HeLa Cells
}

\author{
Vinodini Vijayarangan ${ }^{(}$, Anthony Delalande ${ }^{(}$, Sébastien Dozias, Jean-Michel Pouvesle, \\ Chantal Pichon, and Eric Robert ${ }^{(}$
}

\begin{abstract}
We used a cold atmospheric plasma device as an innovative drug delivery technique in HeLa cells. The focus of this paper is to evaluate key parameters to achieve an efficient cell membrane permeabilization. Propidium iodide (PI) and FITCDextran were used as permeabilization markers. Cellular uptake was assessed by fluorescence microscopy and flow cytometry. Effect of plasma electric field and inhibition of clathrin-mediated endocytosis on plasma-induced permeabilization were studied. Cell viability and reactive oxygen and nitrogen species produced were measured. PI positive cell percentage was the highest for 1000,10000 , and 100000 pulses for 100 -s long treatments. We found that cellular uptake was more efficient after a 30-min incubation time at $37{ }^{\circ} \mathrm{C}$. Unexpectedly, plasma-induced permeabilization appeared to be dependent on endocytosis and plasma electric field did not seem to be responsible for the uptake by itself. No significant toxicity was observed $24 \mathrm{~h}$ after plasma treatment up to 1000 pulses. Level of reactive species produced in the treated medium increased with the number of pulses and peaked using 10000 pulses. Considering a balance between cell viability and drug uptake, best results were obtained for 100-s treatments for 1000 and 10000 pulses. A combined effect between plasma electric field and plasma-induced chemistry seem to be necessary for drug delivery.
\end{abstract}

Index Terms-Cold atmospheric plasma, drug delivery, plasma jet, plasma medicine, plasma-induced permeabilization.

\section{INTRODUCTION}

D RUG delivery consists in different methods to administrate pharmaceutical compounds within the body for therapeutic purposes. There are different types of chemicalbased systems that have been developed for drug delivery into cells or living tissues [1]. Because of the sometime limited selectivity of these methods, physical counterpart techniques are being used and investigated. Advances in this field include the use of ultrasound [2], magnetic fields, and pulsed electric fields [3]. The latter is a method called electroporation. It is

V. Vijayarangan is with the Groupe de Recherche sur l'Energétique des Milieux Ionisés, 45067 Orléans, France, and also with the Centre de Biophysique Moléculaire, 45071 Orléans, France.

A. Delalande and C. Pichon are with the Centre de Biophysique Moléculaire, 45071 Orléans, France (e-mail: anthony.delalande@cnrs.fr).

S. Dozias, J.-M. Pouvesle, and E. Robert are with the Groupe de Recherche sur l'Energétique des Milieux Ionisés, 45067 Orléans, France. a gene transfer method based on the use of electric fields discovered by Neumann et al. [4] in 1982. Its effectiveness has been proven on many models and the mechanisms underlying this technique have been widely studied [5].

Plasma medicine is an innovative field combining plasma physics and medicine to use physical plasma for therapeutic applications [6], [7]. Applications for cancer treatment [8], [9], wound healing [10], sterilization and bacterial decontamination [11], tooth bleaching in dentistry [12], and anti-aging properties for dermatology and cosmetics [13], [14] have been demonstrated and are still subjected to intense research. Nonthermal cold atmospheric plasmas are generated by ionizing gas with an electric discharge device and applied to biological targets. Plasma is an ionized gas with several components including the production of reactive oxygen and nitrogen species (RONS), excited species, photons, UVs, and other radicals or charged particles in the environment of the biological treated target. Beside those species, there also exists intense transient electric field generated in the environment of the plasma, so that some analogy with electroporation can be made and may offer opportunities to use plasma as a new potential drug delivery alternative. The simultaneous delivery of electric field and reactive species may also be a unique way for drug delivery as reported for electrochemotherapy, for which a combination of a chemical drug dose and electric pulse application was optimized [15].

In this paper, the so called plasma gun, designed and routinely used at GREMI, was used for drug delivery assessment. Electric field produced with plasma jets devices have been recently measured to be of a few $\mathrm{kV} / \mathrm{cm}$ in amplitude [16]-[18] in agreement with simulation works [19]. For dielectric barrier discharge (DBD) setups, modeling has shown that beyond these on-target applied electric field, stronger electric field may be generated in deep tissue [20] being above the threshold for electroporation mechanisms triggering. In 2016, Jinno et al. [21] studied how physical, chemical, and biochemical factors played roles in plasmainduced cell membrane permeabilization. They concluded that chemical factors (such as RONS production), while essential to membrane permeabilization, are not sufficient for an effective permeabilization. Indeed, plasma electric field would also play a key role in that process suggesting a synergistic effect of both reactive species production and plasma electric field on transient cell membrane permeabilization. Studies have also discussed plasma electric field effect on cells [22]. 
Synergistic action of plasma and pulsed electric fields [23] but also combinatory action of plasma generated reactive species, plasma associated transient electric fields, and charged particles [24] were recently shown to be likely to explain the interaction with biological membranes leading to an efficient antibacterial action during such innovative protocols.

It turns out that according to the literature the use of plasma can also allow gene transfer (high-weight molecular uptake). Ogawa et al. [25] initiated this technique in 2005, thus transfecting neuronal cells (known to be difficult to transfect using electroporation) with plasmid DNA encoding GFP by plasma treatment. The plasma used in that study was an air plasma from a device initially used for treating nonbiological surfaces. Following this first study Sakai et al. [26] also used a plasma generator for transfection and flow cytometry to measure transfection efficiency. They stated that the mechanisms involved in plasma-induced transfection could be similar to electroporation. The locally generated plasma electric field would allow transient cell membrane permeability. Plasmid concentrations used in this paper were, however, very high suggesting that the real efficiency of plasma-induced transfection is still to be fully understood. In 2009, Leduc et al. [27] studied the effect of an atmospheric pressure glow discharge-torch on biological targets. They observed HeLa cell membrane permeabilization of a small 10-kDa Dextran molecule [27]. They observed a local treatment of the cell layer surface. Kaneko et al. [28] have permeabilized fibroblasts with helium plasma using YOYO-1, a DNA intercalating fluorescent dye inside the nucleus. They observed a local cell detachment with high permeabilization on the border and the middle of the treated area.

Two pathways for molecular uptake can be used; endocytosis (clathrin or caveolin-mediated endocytosis, micropinocytosis) and through the formation of cell membrane pores. Assessment of pore sizes can be achieved by using molecules of different weight. In this paper, we investigated the plasma treatment parameters that allowed an efficient delivery of cargo molecules with different sizes. Then, we investigated whether the delivery was governed either by the chemical (RONS) or physical (electric field) effects of the plasma treatment. Last, we also assessed the impact of clathrin-mediated endocytosis and plasma electric field on cellular uptake.

\section{Materials AND MethodS}

\section{A. Chemicals}

All reagents were purchased from Sigma-Aldrich.

\section{B. Experimental Setup}

Helium plasma was generated with a device from GREMI called plasma gun. This system is a plasma jet based on a DBD reactor with a coaxial geometry powered by microsecond voltage pulses. High purity helium gas (Alphagaz 1, Air Liquide) was flushed at $0.5 \mathrm{slm}$ through the reactor which led to plasma ignition between the two electrodes. Gas flow rate was controlled by a digital mass flow meter (red-y compact series, Vögtlin instruments). As shown in Fig. 1, the DBD reactor

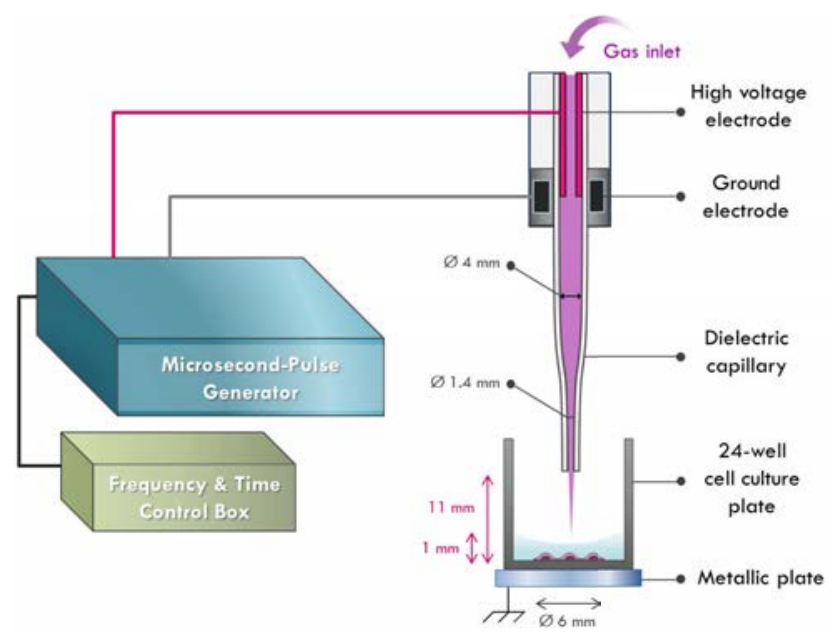

(a)

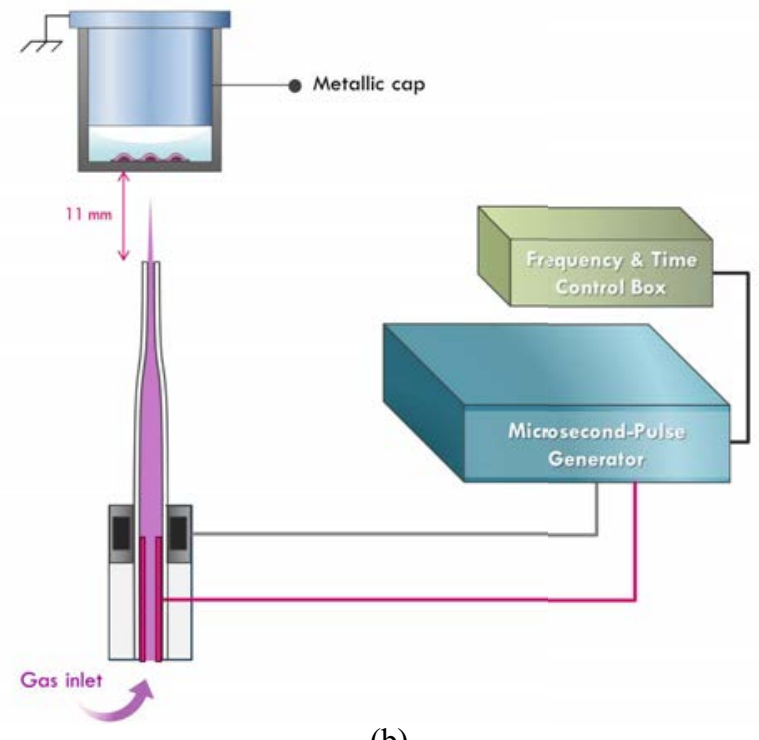

(b)

Fig. 1. Scheme of the "plasma gun" setup for (a) direct plasma treatment and (b) plasma electric field treatment.

consists of an inner high voltage hollow electrode (2-cm long, inner diameter $0.8 \mathrm{~mm}$ ) and an outside grounded ring electrode set on the outer surface of a borosilicate capillary. Both voltage pulse rise time and full width at half maximum are $2 \mu \mathrm{s}$ for an applied voltage of $14 \mathrm{kV}$. Frequencies used ranged from 10 to $1000 \mathrm{~Hz}$. Positive polarity was set. Plasma generated then propagated in the capillary before reaching ambient air. The dielectric capillary was $12-\mathrm{cm}$ long and tapered in the last $2 \mathrm{~cm}$ (lower part), the inner diameter was $4 \mathrm{~mm}$ in the upper part and $1.4 \mathrm{~mm}$ in the lower part, glass thickness was $1 \mathrm{~mm}$.

\section{Cell Culture}

$5 \times 10^{4}$ HeLa cells (Human cervical cancer cells, ATCC CCL-2) were seeded in the center of 24-well plates (Sarstedt polystyrene plate; 83.3922.005) to reach full confluence after $24 \mathrm{~h}$. In order to achieve a seeded area corresponding to a circle of $6 \mathrm{~mm}$ in diameter (around $28 \mathrm{~mm}^{2}$ ) in the center of the well, droplets of $100 \mu \mathrm{L}$ containing cells were carefully set 
in the center of the well. Plates were incubated overnight in this configuration. HeLa cells were grown in minimum essential medium supplemented with $10 \%$ fetal calf serum (FCS), $1 \%$ penicillin/streptomycin (P/S), $1 \%$ GlutaMAX and 1\% nonessential amino acids. Cells were detached with trypsin twice a week, medium was changed every two to three days and were incubated at $37{ }^{\circ} \mathrm{C}$ in a humidified atmosphere containing 5\% $\mathrm{CO}_{2}$. Cells were also tested whether they were mycoplasma free (MycoAlert, Lonza).

\section{Cell Membrane Permeabilization Analysis}

Propidium iodide (PI) and FITC-Dextran (70 and $150 \mathrm{kDa}$ ) were used as molecular markers for membrane permeabilization at, respectively, $50 \mu \mathrm{g} / \mathrm{mL}$ and $1 \mathrm{mg} / \mathrm{mL}$ per well. Both PI and FITC-Dextran were added to each well right before plasma treatment. Membrane permeabilization was assessed either right after treatment or after a 30-min incubation time at $37{ }^{\circ} \mathrm{C}$. The percentage of permeabilized cells was measured by flow cytometry (BD, LSRII); PI fluorescence was read in FL-2 channel. For each condition 10000 events were collected in the gate corresponding to HeLa cells. For fluorescence imaging, cells were observed by microscopy using an inverted microscope Axiovert200 (AxioCam MRm, HBO $100 \mathrm{~W}$ lamp, FluoArc, Zeiss) equipped with a $10 \times$ objective (Zeiss) for both PI and FITC-Dextran for fluorescent probe uptake visualization. Cells were fixed after plasma treatment with a solution of PBS containing $2 \%$ paraformaldehyde during $30 \mathrm{~min}$ at $37{ }^{\circ} \mathrm{C}$ prior imaging. To be comparable, all images were taken with the same exposure time.

\section{E. Plasma Treatment}

Cells were treated $24 \mathrm{~h}$ after seeding. Wells were washed with phosphate buffer saline (PBS) and cells were treated in Opti-MEM culture media with $1 \%$ FCS and $1 \%$ P/S $(200 \mu \mathrm{L}$ per well). The culture plate was positioned on a grounded metallic plate during plasma treatment [Fig. 1(a)]. Capillaryto-cells distance was set at $11 \mathrm{~mm}$ (capillary-to-medium surface was around $10 \mathrm{~mm}$ ).

\section{F. Plasma Electric Field Treatment}

Plasma was applied under a 24-well plate in order to expose the cells only to the electric field generated with the device. A grounded cap was set into the treated well above the medium to obtain during electric field alone treatment, an electric field configuration close to that encountered with plasma treatment. Capillary to cells distance was kept at $11 \mathrm{~mm}$ [Fig. 1(b)]. PI positive cell percentage was measured after flow cytometry analysis. In these experiments, controls used were cells incubated with PI only.

\section{G. Clathrin-Mediated Endocytosis Inhibition}

Cells were incubated with a $5-\mu \mathrm{g} / \mathrm{mL}$ solution of chlorpromazine for $30 \mathrm{~min}$ at $37{ }^{\circ} \mathrm{C}$. The dilution was prepared in Opti-MEM (1\% FCS and 1\% P/S). Before plasma treatment, cells were washed with PBS and treated as described in the plasma treatment paragraph. PI positive cell percentage was measured after flow cytometry analysis. In these experiments, controls used were cells incubated with chlorpromazine only.

\section{H. RONS Quantification in Plasma-Treated Medium Using Dihydrorhodamine 123 (DHR 123)}

RONS production was assessed by a fluorometric assay using DHR 123 (Sigma). Cells were incubated for $45 \mathrm{~min}$ with a $10 \mu \mathrm{M}$ solution of DHR 123 in Opti-MEM culture medium and thoroughly washed before plasma treatment. Fluorescence was measured after treatment using spectrophotometry at $535 \mathrm{~nm}$ (Victor ${ }^{3} \mathrm{~V}$, PerkinElmer).

\section{Cell Viability Assay}

Cell viability was assessed using the XTT assay kit (Roche) $24 \mathrm{~h}$ after plasma treatment. Absorbance was measured with spectrophotometry at 450 and $650 \mathrm{~nm}\left(\right.$ Victor $\left.^{3} \mathrm{~V}\right)$. Viability was calculated as the ratio of the absorbance of treated cells over untreated control, this ratio was normalized as a percentage.

\section{J. Statistical Analysis}

Results were plotted as mean \pm standard deviation. Twoway ANOVA test was used to check the statistical significance and $p$-value using GraphPad Prism 6 software (* for $p<0.05$, $* * *$ for $p<0.001)$

\section{RESUlTS AND Discussion}

Fig. 2 shows the uptake of PI (668 Da), 70- and 150-kDa FITC-Dextran into HeLa cells $30 \mathrm{~min}$ after plasma treatment. Frequency was set at $10 \mathrm{~Hz}$ and the treatment time at $100 \mathrm{~s}$ corresponding to 1000 pulses. A detachment of the cells in a circular shape $(\sim 1-\mathrm{mm}$ diameter $)$ was observed immediately after plasma treatment. This detachment was always observed and could be due to the mechanical stress produced by plasma or by the electric field; this could also be due to an effect of short lifetime chemical species. This phenomenon has been observed by others [28]. It has to be noted that cells were grown at confluence for the experiment in order to have all cells treated by the plasma. Note that when experiments were done with a lower confluence level, detachment was still observed (not shown). Cells on the border of the detachment area were highly permeabilized when using PI and $70-\mathrm{kDa}$ FITC-Dextran. However, the entry of $150-\mathrm{kDa}$ FITCDextran was less efficient, few cells were fluorescent and the signal was weaker. For all molecules, the fluorescence signal decreased as a function of the distance to the detachment area; this observation suggests that permeabilization is localized around the plasma treated area. A threshold in the size of the molecules delivered observed suggests that the molecular weight of the drug to deliver is important, as already reported by Leduc et al. [27] for same cell type but a different plasma source. The drug could be delivered through the formation of a pore with an estimated diameter of $6.5 \mathrm{~nm}$ which corresponds to 70-kDa Dextran size [29].

We investigated the number of pulses needed for an efficient PI cellular uptake (Fig. 3). 100 to 100000 pulses with 


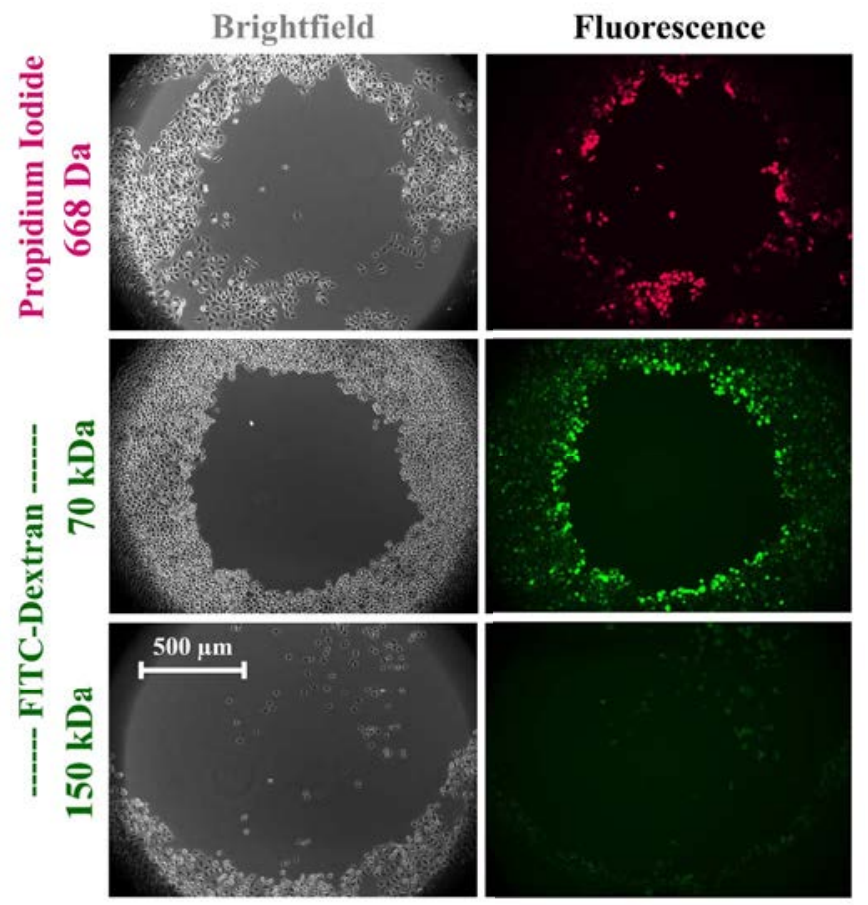

Fig. 2. Microscopic observation of fluorescence in HeLa cells 30 min after treatment with 1000 pulses of plasma $(10 \mathrm{~Hz}$ during $100 \mathrm{~s})$ in the presence of PI, 70- or 150-kDa FITC-Dextran (10× objective).

frequencies at 10,100 , or $1000 \mathrm{~Hz}$ and treatment times of either 10 or $100 \mathrm{~s}$ were tested. Results show that immediately after plasma treatment the PI cellular uptake was not significantly higher than the control. The maximum was reached with 10000 pulses leading to $4.72 \pm 3.01 \%$ PI positive cells compared to $2.42 \pm 1.15 \%$ for the untreated control. We also studied whether the effect of plasma was mainly occurring during plasma treatment or if it is a long-term effect due to reactive species produced in the media. After $30 \mathrm{~min}$ of incubation, the uptake was higher for all the plasma conditions. The percentage of permeabilized cells after incubation was at $21.57 \pm 6.28 \%, 17.67 \pm 4.29 \%$, and $20.73 \pm 3.73 \%$ for 1000 (10 Hz during $100 \mathrm{~s}$ ), 10 000, and 100000 pulses, respectively, which was, on average, seven times higher than in the untreated control. It has to be noted that the percentage of PI positive cells in the control group corresponds to cells undergoing apoptosis. This has to be differentiated from PI uptake induced by plasma treatment. Indeed, cells were treated using the same parameters but incubated with PI only right before the flow cytometry analysis (i.e., 30-min post treatment). In these operating conditions, no significant PI uptake, likely to be associated with apoptosis induction, was measured (not shown). It is important to note that the percentage of cell detachment area in the 1000-pulse condition was estimated to be only around $3 \%$. A maximum of $11 \%$ was found in the 100 000-pulse condition. Those calculations have been made considering a seeded surface of $28 \mathrm{~mm}^{2}$ and cell detachment areas between 0.8 and $3 \mathrm{~mm}^{2}$. However, considering that the permeabilized area is in the center of the well, permeabilization efficiencies could be underestimated by a factor 3 or 4 .

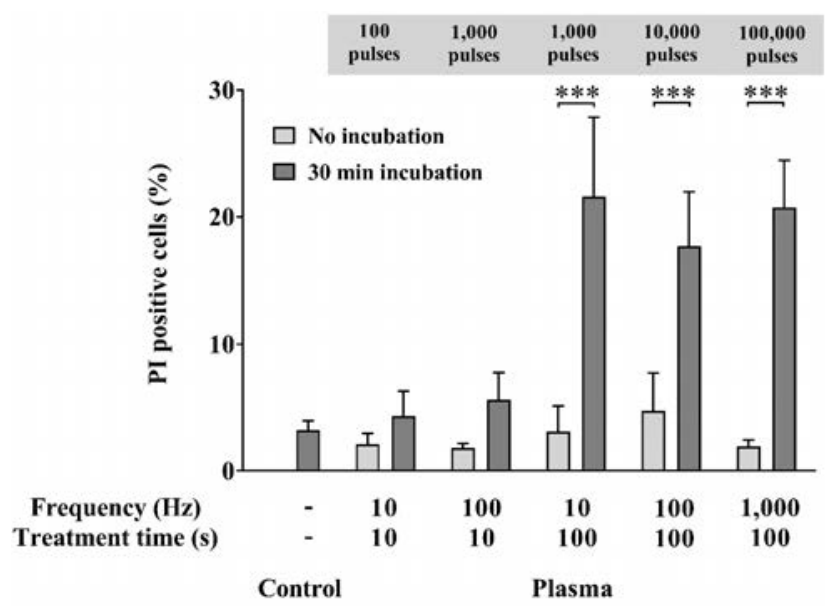

Fig. 3. Evaluation of the number of pulses, frequency and treatment time on PI cellular uptake on HeLa cells immediately and after $30 \mathrm{~min}$ of incubation $(n=3)$.

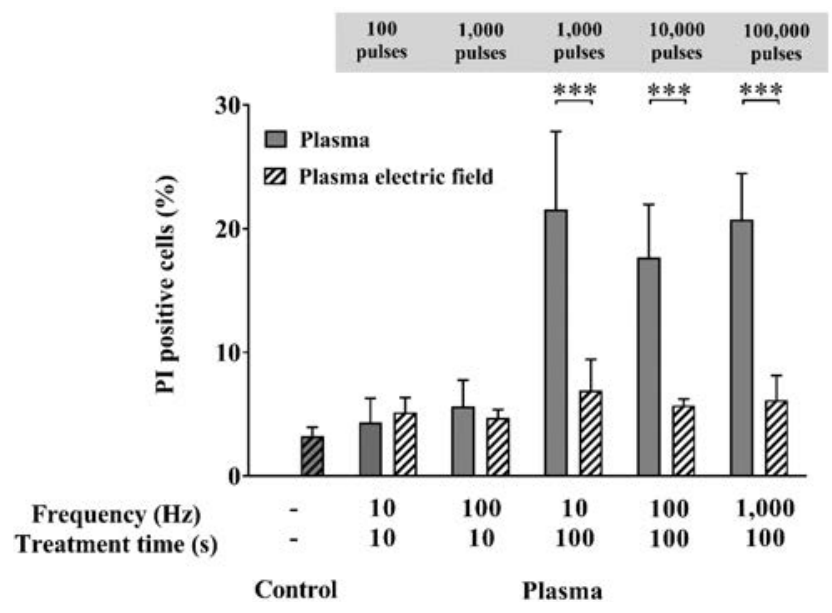

Fig. 4. Impact of plasma electric field on PI cellular uptake in HeLa cells after $30 \mathrm{~min}$ of incubation $(n=3)$.

Using the same number of pulses, a 100-s plasma treatment $(10 \mathrm{~Hz})$ led to a much higher (3.84 times) PI uptake compared to the $10-\mathrm{s}(100 \mathrm{~Hz})$ plasma treatment. This result suggests that the cell resting time between two pulses is an important parameter to get an efficient uptake. For $10 \mathrm{~Hz}$, the delay between successive pulses is of $100 \mathrm{~ms}$ while this is reduced to $10 \mathrm{~ms}$ for $100-\mathrm{Hz}$ pulse repetition rate. Reactive species having a lifetime of a few tens of milliseconds may then be of importance for drug uptake. Permeabilization was more efficient when cells were incubated with the treated medium for 30 min at $37^{\circ} \mathrm{C}$, likely indicating that both long-term and secondary species produced with plasma play a key role in cell membrane permeabilization.

To assess whether the electric field generated with plasma was involved in cell membrane permeabilization after 30 min of incubation, cells were treated with plasma electric field alone (Fig. 4). While this specific configuration does not accurately replicate the electric field exposed to the cells during regular plasma treatments, it offers a close comparative tool to assess plasma electric field involvement in molecular uptake. The use of plasma electric field alone significantly 
reduced PI uptake, for 1000 pulses at $10 \mathrm{~Hz}$ the percentage of PI positive cells reached was of $6.93 \pm 2.52 \%$ compared to $21.57 \pm 6.28 \%$ for the plasma condition. Those results suggest that the molecular entry into cells is not only triggered by plasma electric field but that chemical species are also necessary for cell permeabilization. The ring shape of the PI and dextran uptake documented in Fig. 2 are difficult to correlate solely with the action of RONS generated by the plasma jet and kept in contact with cell for long duration $(30 \mathrm{~min})$. One hypothesis is that besides, electric field only is not very efficient for molecule penetration in cells; it may play a role, eventually as a combination with long but also short lifetime reactive species present during plasma delivery, on cell membrane. While more detailed measurement should be performed to confirm or reject this hypothesis, one may imagine that both electric field and short lifetime reactive species are mostly present around the plasma jet impact area. However, it does not exclude a possible combined effect between plasma electric field and plasma-triggered chemical processes into cells and/or in the medium surrounding cells. Cell membranes subjected to the electric field are probably charged which would allow transient pore opening as described by others during electroporation [30]. However, the electric field applied to the cells is different in plasma treatment compared to electroporation. Electroporation by intense electric fields acting over nanosecond time durations has already been reported [31]-[33] Electroporation protocols are mostly using eight pulses of $100-\mu$ s duration with electric field amplitudes in the order of several $\mathrm{kV} / \mathrm{cm}$. Plasma jet treatments usually consist in the delivery of thousands of pulses delivered in the kilohertz regime. With microsecond duration pulsed operation, as for the plasma gun used in this paper, the electric field is the combination of two components. One component is intense, from a few $\mathrm{kV} / \mathrm{cm}$ to a few tens of $\mathrm{kV} / \mathrm{cm}$ in amplitude, and very transient on nanosecond timescale. The second component has a longer duration, on microsecond timescale, and a lower amplitude of a few $\mathrm{kV} / \mathrm{cm}$ [18]. Yusupov et al. [34] showed by molecular dynamic simulations that peroxidation of the cell membrane lipids caused by plasma RONS resulted in a drop of the electric field threshold needed for pore formation.

We studied the involvement of clathrin-mediated endocytosis, which is the major entry pathway in the cell, on plasmainduced PI uptake. Fig. 5 shows that the use of chlorpromazine induced a significant inhibition of PI uptake, the percentage of PI positive cells decreased by $2.67,1.92$, and 2.89 times for 1000 pulses at $10 \mathrm{~Hz}, 10000$ and 100000 pulses, respectively. Those results therefore suggest that cell membrane pores are not the only responsible for cellular uptake but in addition clathrin-mediated endocytosis pathway also occurred. The fact that no significant uptake was found when the measurement was done right after the plasma treatment compared to $30 \mathrm{~min}$ after incubation at $37{ }^{\circ} \mathrm{C}$, is in line with the involvement of endocytosis (as shown in Fig. 3). However, this period of time could also be crucial for the RONS effect on the integrity of the plasma membrane.

It is widely known that plasma induces the production of RONS in both treated medium and treated cells. We measured

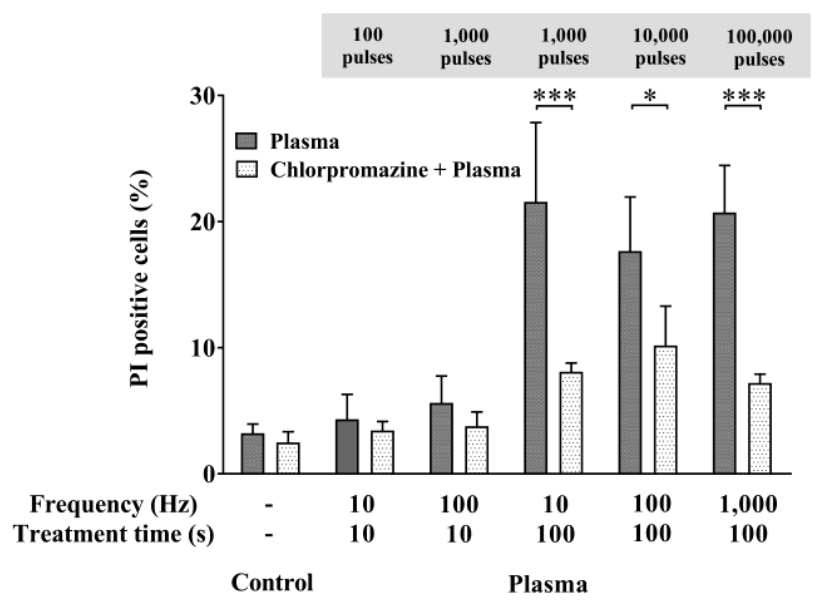

Fig. 5. Effect of the inhibition of clathrin-mediated endocytosis on PI cellular uptake in HeLa cells 30 min after plasma treatment $(n=3)$.

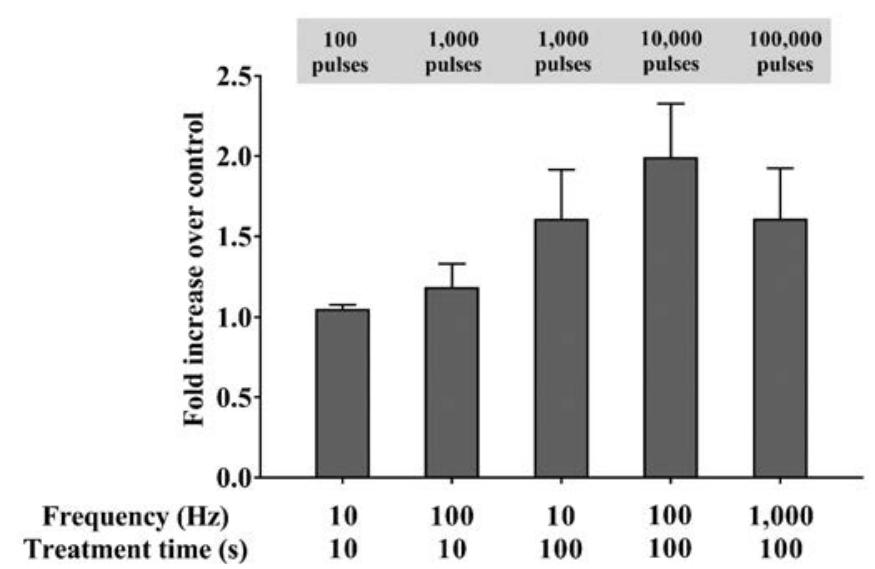

Fig. 6. Analysis of RONS production $30 \mathrm{~min}$ after plasma treatment using DHR 123 fluorescent probe. Results are expressed as fold increase over untreated control $(n=3)$.

the general amount of species produced in the medium when HeLa cells were treated with plasma. We used DHR 123 fluorescent probe as a RONS indicator. DHR 123 can passively diffuse across cell membranes it is then oxidized as a cationic rhodamine 123 which localizes in the mitochondria and exhibits a green fluorescence. DHR 123 is a nonspecific RONS indicator; it is commonly used to detect peroxynitrites [35]. Fig. 6 shows that compared to control the level of fluorescence was increased with the number of pulses from $1.05 \pm 0.02$ at 100 pulses to $1.99 \pm 0.33$ times at 10000 pulses compared to control cells. However, for 100000 pulses, the fluorescence slightly dropped to $1.61 \pm 0.31$ probably due to a higher cell detachment hence a lower number of adherent stressed cells. Furthermore, mitochondria depolarization can also result in a change in membrane potential and might prevent the entrance of DHR However, in our settings, even though mitochondria potential membrane was modified during plasma treatment, our results showed that the RONS produced during plasma delivery, kept being active, at least for those having a long lifetime, $30 \mathrm{~min}$ after plasma treatment. At this time point, the mitochondria membrane potential should have been restored. RONS produced during plasma 


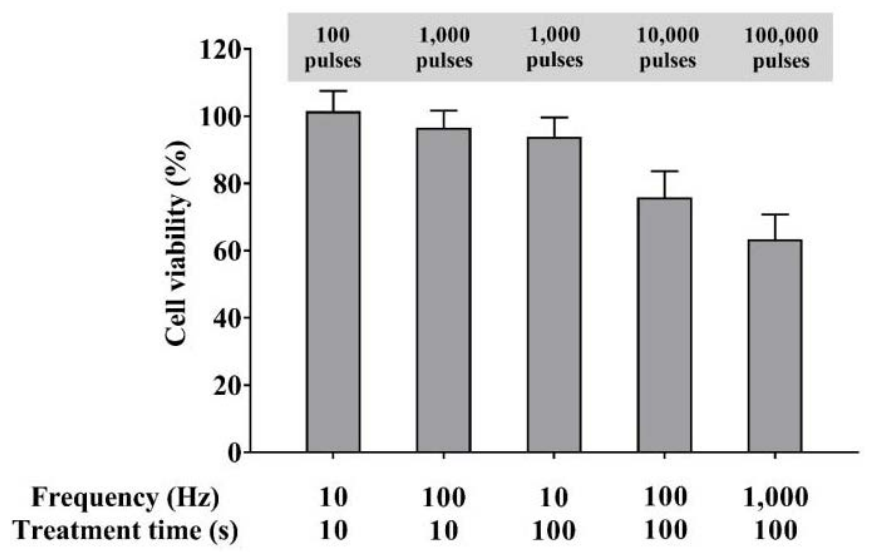

Fig. 7. Cell viability $24 \mathrm{~h}$ after plasma treatment on HeLa cells $(n=4)$.

treatment act efficiently mainly if a 30-min incubation period is applied while we suspect that mitochondria membrane potential perturbation should be a transient effect, mostly active during plasma delivery. Moreover, even if it could have modified our results, we could still see differences between our plasma treatments and the untreated (nondepolarized) control. A higher fluorescence fold increase compared to control with the condition at 10000 pulses $(100 \mathrm{~Hz}$ during 100 s) compared to 100000 pulses could also be explained by the fact that the latter condition was too strong inducing more cell detachment and RONS production seemed to be tampered.

As shown in Fig. 7, the cell viability measured $24 \mathrm{~h}$ after plasma treatment was not altered with $100-$ and 1000pulse treatments. However, for 10000 and 100000 pulses, viability dropped to $75.90 \pm 7.80 \%$ and $63.44 \pm 7.32 \%$, respectively. The threshold value for cell toxicity seems to be 10000 pulses, much higher than that leading to the cell detachment; 1000 pulses. Taking into account both uptake and cell viability efficiencies, the 1000-pulse condition seemed to be the most suitable $(93.96 \pm 5.73 \%$ of cell viability and $21.57 \pm 6.28 \%$ of PI positive cells). Because of cell detachment occurring during plasma exposure, cell membrane permeabilization could be underestimated. Moreover, as the plasma treatment area was very narrow $\left(0.8\right.$ to $\left.3 \mathrm{~mm}^{2}\right)$, cells on the well were not uniformly subjected to plasma (seeded surface of $28 \mathrm{~mm}^{2}$ ). For measurement of PI positive cells, cells from the wells have to be detached for flow cytometry analysis. This led to an underestimation of permeabilized cells percentage in the treated area which is smaller than the seeded surface. Similarly, cell viability is also difficult to assess because of this cell detachment. On one side, the cell viability is certainly much lower in the plasma treated well because cells that were mechanically detached under plasma treatment have not been taken into account. On the other side, all cells seeded in the well were subjected to long term species produced by the plasma treatment. Those, species seem to be mainly responsible for the molecular uptake. Note that previous works have reported that nanosecond pulsed electric fields and plasma treatment could lead to high level of cytotoxicity [24], [36].

\section{CONCLUSION}

In this paper, we investigated the plasma parameters and conditions for efficient drug delivery. Using a plasma gun device, best results, combining efficient molecular uptake and low toxicity, were found for a plasma treatment time of $100 \mathrm{~s}$ at frequencies ranging between 10 and $100 \mathrm{~Hz}$ (corresponding to a number of applied pulses between 1000 and 10 000). Interestingly, the delay between each pulse is a key parameter for cell membrane permeabilization. Our results on plasma electric field and chlorpromazine incubation led us to hypothesize that whilst having their own specific effect on molecular uptake, both RONS produced by plasma and plasma electric field induce membrane pore formation. However, endocytosis appears to be mainly linked to plasma-induced RONS. To summarize, a combined effect between plasma electric field and reactive species produced in the treated medium is necessary to ensure the effectiveness of plasma jets as an efficient drug delivery device and an innovative therapy.

\section{ACKNOWLEDGMENT}

The authors would like to thank Dr. G. Busco for his help on plasma-induced RONS measurements and suggestions and discussion in this paper.

\section{REFERENCES}

[1] G. Tiwari et al., "Drug delivery systems: An updated review," Int. J. Pharm. Invest., vol. 2, no. 1, p. 2-11, 2012.

[2] L. B. Feril, Jr., and K. Tachibana, "Use of ultrasound in drug delivery systems: Emphasis on experimental methodology and mechanisms," Int. J. Hyperthermia, vol. 28, no. 4, pp. 282-289, 2012.

[3] C. Rosazza, S. H. Meglic, A. Zumbusch, M.-P. Rols, and D. Miklavcic, "Gene electrotransfer: A mechanistic perspective," Current Gene Ther, vol. 16, no. 2, pp. 98-129, 2016.

[4] E. Neumann, M. Schafer-Ridder, Y. Wang, and P. H. Hofschneider, "Gene transfer into mouse lyoma cells by electroporation in high electric fields," $E M B O ~ J .$, vol. 1, no. 7, pp. 841-845, 1982.

[5] J. M. Escoffre et al., "What is (still not) known of the mechanism by which electroporation mediates gene transfer and expression in cells and tissues," Mol. Biotechnol., vol. 41, no. 3, pp. 286-295, 2009.

[6] K.-D. Weltmann and T. von Woedtke, "Plasma medicine-Current state of research and medical application," Plasma Phys. Controlled Fusion, vol. 59, no. 1, 2016, Art. no. 014031.

[7] M. G. Kong et al., "Plasma medicine: An introductory review," New J. Phys., vol. 11, no. 11, 2009, Art. no. 115012.

[8] L. Brullé et al., "Effects of a non thermal plasma treatment alone or in combination with gemcitabine in a MIA PaCa2-luc orthotopic pancreatic carcinoma model," PLoS One, vol. 7, no. 12, pp. 1-10, 2012.

[9] J. Schlegel, J. Köritzer, and V. Boxhammer, "Plasma in cancer treatment," Clin. Plasma Med., vol. 1, no. 2, pp. 2-7, 2013.

[10] G. Isbary et al., "Cold atmospheric argon plasma treatment may accelerate wound healing in chronic wounds: Results of an open retrospective randomized controlled study in vivo," Clin. Plasma Med., vol. 1, no. 2, pp. 25-30, 2013.

[11] H. Shintani, A. Sakudo, P. Burke, and G. McDonnell, "Gas plasma sterilization of microorganisms and mechanisms of action," Exp. Ther. Med., vol. 1, no. 5, pp. 731-738, Sep./Oct. 2010.

[12] S. H. Nam, H. J. Lee, J. W. Hong, and G. C. Kim, "Efficacy of nonthermal atmospheric pressure plasma for tooth bleaching," Sci. World J., vol. 2015, pp. 18-22, Jan. 2015.

[13] J.-H. Choi, H.-W. Lee, J.-K. Lee, J. W. Hong, and G. C. Kim, "Lowtemperature atmospheric plasma increases the expression of anti-aging genes of skin cells without causing cellular damages," Arch. Dermatol. Res., vol. 305, no. 2, pp. 133-140, 2013.

[14] S. H. Bentkover, "Plasma skin resurfacing: Personal experience and long-term results," Facial Plast. Surg. Clinics North Amer., vol. 20, no. 2, pp. 145-162, 2012. 
[15] C. Y. Calvet and L. M. Mir, "The promising alliance of anti-cancer electrochemotherapy with immunotherapy," Cancer Metastasis Rev., vol. 35, no. 2, pp. 165-177, 2016.

[16] E. Robert, T. Darny, S. Dozias, S. Iseni, and J. M. Pouvesle, "New insights on the propagation of pulsed atmospheric plasma streams: From single jet to multi jet arrays," Phys. Plasmas, vol. 22, no. 12, Nov. 2015 , Art. no. 122007.

[17] G. B. Sretenović, I. B. Krstić, V. V. Kovaćević, B. M. Obradović, and K. M. Milorad, "Spatio-temporally resolved electric field measurements in helium plasma jet," J. Phys. D Appl. Phys., vol. 47, no. 10, 2014, Art. no. 102001.

[18] T. Darny et al., "Analysis of conductive target influence in plasma jet experiments through helium metastable and electric field measurements," Plasma Sources Sci. Technol., vol. 26, no. 4, 2017, Art. no. 45008.

[19] A. Bourdon et al., "Numerical and experimental study of the dynamics of a $\mu$ s helium plasma gun discharge with various amounts of $\mathrm{N}_{2}$ admixture," Plasma Sources Sci. Technol., vol. 25, no. 3, 2016 , Art. no. 35002 .

[20] N. Y. Babaeva and M. J. Kushner, "Intracellular electric fields produced by dielectric barrier discharge treatment of skin," J. Phys. D Appl. Phys., vol. 43, no. 18, 2010, Art. no. 185206.

[21] M. Jinno, Y. Ikeda, H. Motomura, Y. Kido, and S. Satoh, "Investigation of plasma induced electrical and chemical factors and their contribution processes to plasma gene transfection," Arch. Biochem. Biophys. vol. 605, pp. 59-66, Sep. 2016.

[22] M. Dezest et al., "Oxidative modification and electrochemical inactivation of Escherichia coli upon cold atmospheric pressure plasma exposure," PLoS One, vol. 12, no. 3, Mar. 2017, Art. no. e0173618.

[23] Q. Zhang et al., "Synergistic antibacterial effects of treatments with low temperature plasma jet and pulsed electric fields," Appl. Phys. Lett., vol. 105 , no. 10 , Sep. 2014, Art. no. 104103.

[24] W. Zhu et al., "Synergistic effect of cold atmospheric plasma and drug loaded core-shell nanoparticles on inhibiting breast cancer cell growth," Sci. Rep., vol. 6, Feb. 2016, Art. no. 21974.
[25] Y. Ogawa et al., "An epoch-making application of discharge plasma phenomenon to gene-transfer," Biotechnol. Bioeng., vol. 92, no. 7, pp. 865-870, 2005.

[26] Y. Sakai et al., "A novel transfection method for mammalian cells using gas plasma," J. Biotechnol., vol. 121, no. 3, pp. 299-308, 2006.

[27] M. Leduc, D. Guay, R. L. Leask, and S. Coulombe, "Cell permeabilization using a non-thermal plasma," New J. Phys., vol. 11, pp. 115021-115033, Nov. 2009.

[28] T. Kaneko et al., "Improvement of cell membrane permeability using a cell-solution electrode for generating atmospheric-pressure plasma,' Biointerphases, vol. 10, no. 2, 2015, Art. no. 29521.

[29] J. K. Armstrong, R. B. Wenby, H. J. Meiselman, and T. C. Fisher, "The hydrodynamic radii of macromolecules and their effect on red blood cell aggregation," Biophys. J., vol. 87, no. 6, pp. 4259-4270, 2004.

[30] M. Tarek, "Membrane electroporation: A molecular dynamics simulation," Biophys. J., vol. 88, no. 6, pp. 4045-4053, 2005.

[31] R. P. Joshi and K. H. Schoenbach, "Bioelectric effects of intense ultrashort pulses," Crit. Rev. Biomed. Eng., vol. 38, no. 3. pp. 255-304, 2010.

[32] W. Frey et al., "Plasma membrane voltage changes during nanosecond pulsed electric field exposure," Biophys. J., vol. 90, no. 10, pp. 3608-3615, 2006

[33] Q. Hu, V. Sridhara, R. P. Joshi, J. F. Kolb, and K. H. Schoenbach "Molecular dynamics analysis of high electric pulse effects on bilayer membranes containing DPPC and DPPS," IEEE Trans. Plasma Sci. vol. 34, no. 4, pp. 1405-1411, Aug. 2006.

[34] M. Yusupov, J. Van der Paal, E. C. Neyts, and A. Bogaerts, "Synergistic effect of electric field and lipid oxidation on the permeability of cell membranes," Biochimica et Biophys. Acta (BBA) Gen. Subjects, vol. 1861, no. 4, pp. 839-847, 2017.

[35] N. W. Kooy, J. A. Royall, H. Ischiropoulos, and J. S. Beckman, "Peroxynitrite-mediated oxidation of dihydrorhodamine 123," Free Radic. Biol. Med., vol. 16, no. 2, pp. 149-156, 1994.

[36] S. J. Beebe, N. M. Sain, and W. Ren, "Induction of cell death mechanisms and apoptosis by nanosecond pulsed electric fields (nsPEFs)," Cells, vol. 2, no. 1, pp. 136-162, 2013. 